\title{
Review Article \\ Preclinical and Clinical Effects of RAS Inhibition with a Focus on Telmisartan
}

\author{
Thomas Unger \\ CARIM School for Cardiovascular Diseases, Maastricht University, P.O. Box 616, 6200 MD Maastricht, The Netherlands
}

Correspondence should be addressed to Thomas Unger, t.unger@maastrichtuniversity.nl

Received 20 May 2012; Accepted 10 July 2012

Academic Editors: B. Baudin, C. Kanthou, A. Shaish, and A. Suzuki

Copyright () 2012 Thomas Unger. This is an open access article distributed under the Creative Commons Attribution License, which permits unrestricted use, distribution, and reproduction in any medium, provided the original work is properly cited.

Blockade of the renin-angiotensin system with angiotensin II receptor blockers (ARBs) provides blood pressure (BP)-independent effects throughout the cardiovascular (CV) continuum. In the landmark ongoing telmisartan alone and in combination with ramipril global endpoint trial (ONTARGET), telmisartan reduced CV events in patients at high CV risk, similar to the angiotensinconverting enzyme inhibitor, ramipril. This reduction in CV events is a consequence of non-BP effects on disease pathophysiology which have been demonstrated in preclinical and clinical studies. For example, telmisartan significantly reduces markers of inflammation, such as interleukin-6 and C-reactive protein, and improves markers of vascular function, such as pulse wave velocity. Both these are associated with target organ damage. Telmisartan also has numerous potentially beneficial metabolic effects in preclinical studies. Telmisartan reduces markers of renal disease and its progression, left ventricular hypertrophy, and the risk of primary or secondary atrial fibrillation. Many of these effects are shared with other RAS inhibitors. However, several studies indicate differential effects between telmisartan and other ARBs. These differences probably reflect telmisartan's distinct pharmacologic profile, including the longest plasma half-life, high receptor-binding affinity, and highest lipophilicity of the class. These differences suggest that the results of ONTARGET do not necessarily extrapolate to other ARBs.

\section{Introduction}

The renin-angiotensin system (RAS), and most importantly angiotensin II, is central to the pathogenesis of a variety of clinical conditions along the cardiovascular (CV) continuum, from risk factors such as hypertension and diabetes, to atherosclerosis and left ventricular hypertrophy (LVH), and ultimately to myocardial infarction (MI), stroke, and heart failure (Figure 1) [1-3]. Blockade of the RAS can be achieved at different levels of the system with renin inhibitors, angiotensin-converting enzyme (ACE) inhibitors, or angiotensin II receptor blockers (ARBs). ARBs differ from other RAS blockers in that they block the action of angiotensin II at the angiotensin $\mathrm{AT}_{1}$ receptor but allow continued activation of other receptors-most notably, the angiotensin $\mathrm{AT}_{2}$ receptor. There is little evidence as yet for event-reducing $\mathrm{CV}$ effects of renin inhibitors, beyond blood pressure (BP) reduction, but some ACE inhibitors and ARBs are now proven to reduce the risk of $\mathrm{CV}$ disease in a variety of at-risk patient types, including hypertensive patients, patients with atherosclerosis, LVH, coronary heart disease, heart failure, or diabetic patients with target organ damage, for example, diabetic nephropathy [4-9].

In the ongoing telmisartan alone and in combination with Ramipril global endpoint trial (ONTARGET), telmisartan was the first ARB demonstrated to prevent CV events in patients at high CV risk, similar to the risk reduction with ramipril; importantly, telmisartan was better tolerated than ramipril $[6,10]$. Telmisartan is the only ARB indicated for the reduction of $\mathrm{CV}$ morbidity in patients with manifest atherothrombotic CV disease (history of coronary heart disease, stroke, or peripheral arterial disease) or type 2 diabetes mellitus with documented target organ damage [11]. Agents within the ARB drug class exhibit different pharmacologic profiles $[12,13]$. Telmisartan has a relatively long dissociation half-life from the $\mathrm{AT}_{1}$ receptor and a long plasma half-life $(24 \mathrm{~h})$ compared with other ARBs, thus providing sustained BP control over the whole dosing interval [14]. Telmisartan has a high binding affinity for the $\mathrm{AT}_{1}$ receptor compared with other ARBs, and is highly lipophilic with the 


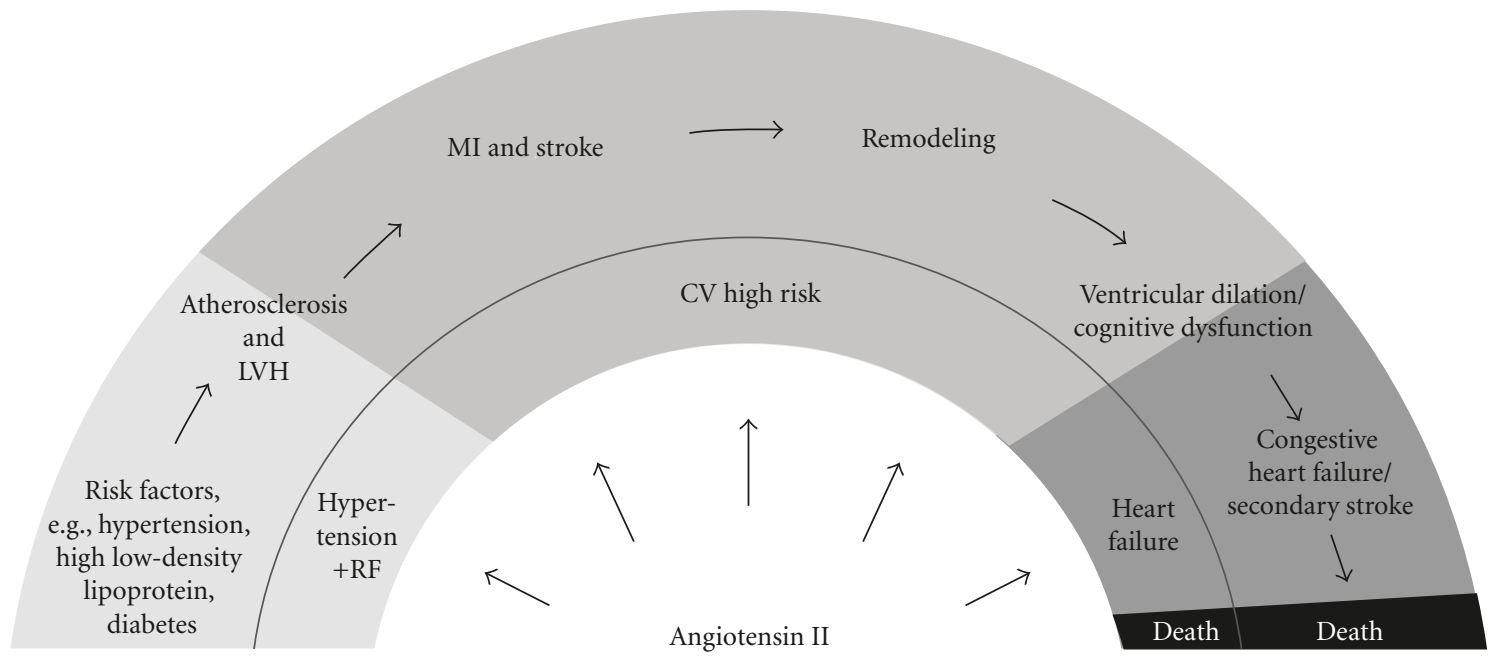

FIgURE 1: The cardiovascular continuum.

greatest volume of distribution [14]. These pharmacologic properties of telmisartan versus other ARBs may translate into differences in clinical outcomes. Although there have been limited comparative clinical studies of CV outcomes with ARBs, there have been a number of studies examining pathophysiologic and intermediate end points. These could shed light on the effects of telmisartan seen in ONTARGET, and in particular whether these effects can be translated into other ARBs.

This review aims to assess the effects of ARBs on CV disease pathophysiologies along the CV continuum. The particular focus will be on telmisartan, to investigate the evidence for a direct effect of this agent on $\mathrm{CV}$ disease processes that may have contributed to the effects on CV outcomes seen in ONTARGET. The bulk of research on telmisartan has investigated aspects of CV disease related to inflammation, vascular function, metabolic status, and target organ damage, such as renal disease and CV and cerebrovascular changes. Within each section, this review will briefly consider the evidence for ARBs in general, before examining the preclinical and clinical evidence on telmisartan, including comparative studies versus other ARBs where they exist. Suitable papers were identified by searching MEDLINE for studies on ARBs that included keywords related to the topics under consideration.

\section{Inflammation}

Inflammation is involved in the pathogenesis and continuation of atherosclerosis and contributes to the development of hypertension and its complications [15]. Angiotensin II acts as a proinflammatory cytokine, inducing inflammation through the upregulation of reactive oxygen species, adhesion molecules, and inflammatory cytokines [16]. Therefore, RAS inhibition has the potential to reduce inflammation in patients at risk of CV disease, and this is supported by several in vitro studies. For example, losartan (as well as captopril or amlodipine, but not atenolol or hydrochlorothiazide (HCTZ)) produced marked anti-inflammatory effects at clinically relevant serum concentrations, as shown by interleukin-1 beta (IL-1 $\beta$ ) secretion by polymorphonuclear leukocytes from patients with essential hypertension [17].

Studies in humans have confirmed these effects. In two studies of hypertensive patients with or without diabetes, valsartan or candesartan for 6 months decreased serum highsensitivity C-reactive protein (hs-CRP) and IL-6 [18, 19]. In another study of high-risk hypertensive diabetic patients with high baseline IL-6 (>2.0 ng/L; $n=54)$, valsartan $320 \mathrm{mg}$ for 16 weeks significantly reduced IL-6 (a decrease from 3.5 to 2.4 with valsartan $320 \mathrm{mg}$ versus an increase from 3.2 to 3.5 with placebo, $P=0.035$ ) [20]. In a small study of hypertensive patients with coronary artery disease, for 3 months both irbesartan and enalapril significantly reduced serum metalloprotease 9 protein $(P<0.001$ and $P<0.05$, resp.), but only irbesartan reduced hs-CRP and IL-6 (both $P<0.01$ versus baseline) [21]. Another study has shown that olmesartan on a background of HCTZ significantly reduced vascular microinflammation, as shown by serum hsCRP $(-15.1 \% ; P<0.05)$, hs-tumor necrosis factor (TNF) $\alpha$ $(-8.9 \% ; P<0.02)$, IL-6 (-14.0\%; $P<0.05)$, and monocyte chemotactic protein-1 (MCP-1) $(-6.5 \% ; P<0.01)$ versus placebo [22].

Telmisartan has also been shown in animal models to reduce the levels of several markers of inflammation, such as interleukins and TNF $\alpha$. In a rat model, telmisartan protected against experimental autoimmune myocarditis, partly by suppressing inflammatory cytokines and oxidative stress [23]. In this model, compared with vehicle-treated rats, telmisartan decreased myocardial expression of inflammatory cytokines (such as IL-6 and TNF $\alpha$ ), nicotinamide adenine dinucleotide phosphate (NADPH) oxidase subunits, and decreased endoplasmic reticulum stress markers. In an obese mouse model, telmisartan or captopril reduced chemically induced colon carcinogenesis by attenuating chronic inflammation and reducing oxidative stress in obese mice [24]. This was shown by decreased expression of TNF $\alpha$ messenger ribonucleic acid (mRNA) in the colonic mucosa and significantly reduced levels of a marker of oxidative 
damage to deoxyribonucleic acid compared with a control group.

There is some evidence that telmisartan provides greater anti-inflammatory effects than other RAS blockers. In a mouse model, telmisartan reduced atherosclerotic lesion progression and reduced the expression of inflammatory factors to a greater extent than ramipril [25]. In vitro, telmisartan (unlike losartan or its active metabolites EXP-3174 and EXP-3179) reduced endothelial inflammation and oxidative cell damage in human umbilical vein endothelial cells [26].

Consistent with these preclinical studies, telmisartan has shown differential effects in human subjects compared with other ARBs. In hypertensive patients with significant coronary artery stenosis, 8-month treatment with telmisartan (but not valsartan) significantly decreased IL-6 and TNF $\alpha$ as well as late lumen loss $(0.1 \pm 0.4$ versus $0.3 \pm 0.5 \mathrm{~mm} ; P=$ 0.001) [27]. In metabolic syndrome patients, switching from valsartan to telmisartan for 12 weeks significantly reduced hs-CRP (0.77 versus $0.60 \mathrm{mg} / \mathrm{L} ; P=0.022)$ as well as microalbuminuria (28.1 versus $18.9 \mathrm{mg} / \mathrm{g} \cdot \mathrm{Cr} ; P=0.001)$ [28]. In a small study, telmisartan had a more potent antioxidative effect than losartan through its ability to enhance superoxide dismutase activity in type 2 diabetic patients with microalbuminuria. Of note is that oxidative stress induced by excessive superoxide plays a central role in the pathogenesis of diabetic nephropathy.

\section{Arterial Stiffness and Vascular Changes}

Inflammation in the blood vessels triggers a series of pathologic changes, such as endothelial dysfunction calcification, vascular growth, and remodeling [29]. These changes, many of which are moderated by angiotensin II, can lead to arterial wall stiffness, which is an independent predictor of CV events in patients with hypertension [30].

The major evidence for the effects of telmisartan on vascular stiffness comes from studies of pulse wave velocity (PWV), also an independent marker of target organ damage [31]. In the Framingham Heart study, each standard deviation increase in carotid-femoral PWV was associated with a $48 \%$ increase in the adjusted risk of a first major CV event (hazard ratio (HR), 1.48; 95\% confidence interval (CI), 1.161.91; $P=0.002$ ) [30]. Clinical studies show that telmisartan reduces PWV in hypertension [32-35], hypertension plus type 2 diabetes [36, 37], and in hypertension plus chronic kidney disease [38]. Another measure of arterial stiffness is the cardioankle vascular index. In hypertensive patients, 12month treatment with telmisartan had beneficial effects on the cardioankle vascular index, as well as on albuminuria, 24-hour BP, and metabolism compared with calcium channel blockers (CCBs) [39].

Angiotensin II is also involved in the formation of aneurysms [40], and telmisartan has been found to prevent their formation in two animal models. In mice deficient in regulator of G-protein signaling 2 (RGS2; a negative regulator of $\mathrm{AT}_{1}$ receptors), telmisartan reduced the incidence of aneurysms [41]. In rat aortic tissue, telmisartan prevented abdominal aortic aneurysm progression independently of reducing $\mathrm{BP}$, by inhibition of proteolysis, apoptosis, and inflammation [42].

Comparative studies on the vascular effects of ARBs have mainly been conducted in animal models. For example, in a model of stroke-prone hypertensive rats, telmisartan reduced vascular remodeling to a greater degree than losartan, an effect attributed to reduced NADPH oxidase activity [43]. In an in vitro study, telmisartan (but not candesartan, irbesartan, or eprosartan) significantly inhibited the proliferation of vascular smooth muscle cells and cardiac fibroblasts in culture when tested at clinically relevant concentrations [44]. At least one comparative human study has been conducted. In Japanese hypertensive patients, telmisartan provided greater vascular protection than losartan over 1 year, as shown by progression of intima-media thickness of common carotid artery, despite similar BP reductions [45].

\section{Insulin Resistance and New-Onset Diabetes}

Inflammation and vasoconstriction, and the resulting fibrosis, apoptosis, and pancreatic $\beta$-cell death are thought to be the mechanisms that link angiotensin II to metabolic disturbances, such as the development of insulin resistance and new-onset diabetes [46]. RAS blockade improves blood flow and microcirculation in skeletal muscles, which enhances insulin and glucose delivery to the insulin-sensitive tissues, facilitating insulin signaling at the cellular level, and improving insulin secretion by the $\beta$ cells [47]. RAS blockade would also be expected to reverse the deleterious effects of angiotensin II in the pancreas such as fibrosis, inflammation, apoptosis, and $\beta$-cell death [46].

Numerous clinical trials and meta-analyses have found that while diuretics and $\beta$-blockers may worsen insulin resistance and impair glucose tolerance, RAS blockers have the potential for positive metabolic effects [47]. A systematic review of 22 clinical trials involving 143,153 individuals without diabetes showed that the risk of new-onset diabetes was lowest for ARB treatment (8.4\%; odds ratio (OR), 0.57; 95\% CI, 0.46-0.72; $P<0.0001)$, followed by ACE inhibitors (7.1\%; OR, 0.67; 95\% CI, 0.56-0.80; $P<0.0001)$, CCBs (7.2\%; OR, 0.75; 95\% CI, 0.62-0.90; $P=0.002)$, placebo (6.8\%; OR, 0.77; 95\% CI, 0.63-0.94; $P=0.009)$, and $\beta$ blockers (7.6\%; OR, 0.90; 95\% CI, 0.75-1.09; $P=0.30)$ [48].

This reflects the fact that major ARB trials generally reduce new-onset diabetes. The relative risk reduction for new-onset diabetes (as a secondary end point) was 25\% with losartan versus atenolol in hypertensive patients with LVH in the losartan intervention for endpoint reduction in hypertension (LIFE) study $(P=0.001)[4], 23 \%$ with valsartan versus amlodipine in high-risk hypertensive patients in the valsartan antihypertensive long-term use evaluation (VALUE) study $(P<0.0001)[49]$, and $25 \%$ with candesartan versus placebo in hypertensive patients in the study on cognition and prognosis in the elderly (SCOPE) trial $(P=0.09)$ [47]. In the nateglinide and valsartan in impaired glucose tolerance outcomes research (NAVIGATOR) trial, valsartan significantly reduced the development of diabetes compared with placebo in patients with impaired glucose tolerance and one or more CV risk factors (if $\geq 55$ years old) or established 
CV disease (if $\geq 50$ years old) (33.1\% versus $36.8 \%$; $\mathrm{HR}, 0.86$; 95\% CI, 0.80-0.92; $P<0.001)$ [50].

ONTARGET found telmisartan to have a similar effect on new-onset diabetes to ramipril (telmisartan 7.5\%, ramipril $6.7 \%$, and dual RAS blockade 6.1\%) [6]. However, in the telmisartan randomised assessment study in ACE intolerant subjects with cardiovascular Disease (TRANSCEND), which was a parallel study to ONTARGET in 5926 ACE inhibitorintolerant patients [51], telmisartan did not reduce the incidence of new-onset diabetes versus placebo (21.8\% versus 22.4\%; relative risk, 0.95 ; 95\% CI, $0.83-1.10 ; P=0.51$ ) [52]. On the other hand, a combined analysis of TRANSCEND and the prevention regimen for effectively avoiding second strokes (PRoFESS) trial did find a significantly reduction in the incidence of new-onset diabetes by $16 \%$ compared with placebo [53].

In addition to the standard effects of ARBs on angiotensin II-mediated processes, telmisartan acts as a selective peroxisome proliferator-activated receptor gamma (PPAR $\gamma)$ modulator [54, 55]. Although several ARBs exhibit this property, there is a clear order of potency, with telmisartan being the most potent, followed by irbesartan, then losartan [54-56]. Importantly, telmisartan is the only ARB that may modulate PPAR $\gamma$ activation at physiologic plasma concentrations, an effect that is likely to be related to telmisartan high lipophilicity. Several studies have found that telmisartan can influence PPAR $\gamma$ gene expression. In treatmentnaïve hypertensive patients, 3-month telmisartan (but not amlodipine) treatment significantly increased PPAR $\gamma$ mRNA levels $(P=0.006)$ in peripheral monocytes [57], and, in treatment-naïve patients with the metabolic syndrome, highdose (160 mg once daily) telmisartan for 14 weeks induced monocytic PPAR $y$ genes [58]. An in vitro study found that telmisartan, but not candesartan or losartan, upregulated PPAR $\gamma$ expression [59]. However, other ARBs may also have some clinically meaningful PPAR $\gamma$ activity in one study in humans, treatment with losartan for 2 months increased PPAR $\gamma$ genes versus no treatment in monocytes, probably through the action of the transient losartan aldehyde metabolite, EXP3179 [60].

Numerous in vitro and animal studies have compared the effects of telmisartan with other RAS blockers on metabolic outcomes. Telmisartan or perindopril similarly protected pancreatic islet function in rats fed a high-fat diet; mechanisms included downregulation of islet inflammation, oxidative stress, endoplasmic reticulum stress, and apoptosis [61]. In rats, telmisartan or irbesartan (not eprosartan) induced adiponectin in adipocytes, and this was associated with improved insulin sensitivity [62]. In an in vitro study, telmisartan, but not candesartan, increased glucose transporter 4 levels at the plasma membrane [63]. In one study, both telmisartan and the PPAR $\gamma$ agonist, rosiglitazone, reduced adipose tissue inflammation (measured by markers such as MCP-1) and improved insulin resistance and glucose intolerance in a diet-induced obesity mouse model [64]. Similarly, both telmisartan or rosiglitazone, but not valsartan, ameliorated hyperglycemia and the metabolic profile in diabetic hypertensive rats via PPAR $\gamma$ modulation [65].
Comparative studies in humans are also common but are generally characterized by small patient numbers [66]. Broadly speaking, however, these studies show that telmisartan provides greater efficacy than other ARBs [66]. In a randomized, open-label, 24-week study, telmisartan/rosuvastatin provided favorable effects compared with irbesartan/rosuvastatin or olmesartan/rosuvastatin on glucose metabolism in patients with hypertension, impaired fasting glucose, and dyslipidemia [67]. Telmisartan, but not olmesartan, improved adiponectin levels in hypertensive patients with glucose intolerance [68]. In patients with the metabolic syndrome, telmisartan improved glucose sensitivity versus losartan [69], valsartan [70], and irbesartan [71]. Telmisartan also improved glucose sensitivity versus irbesartan in nondiabetic, obese, and insulin-resistant hypertensive patients $[71,72]$. Another study found a benefit with telmisartan but not olmesartan in overweight/obese hypertensive patients [73]. Several studies have found that replacement of valsartan or candesartan with telmisartan improved fasting plasma insulin or glucose [74-76].

Overall, these studies confirm the beneficial metabolic profile of ARBs and point towards potential differences in the metabolic effects of telmisartan compared with other ARBs. Such differences may be linked to the PPAR $\gamma$-modulating effects of telmisartan, or could be a consequence of other pharmacologic differences. However, in the absence of clear evidence of differences in larger trials, the clinical implications of these difference remain uncertain.

\section{Albuminuria and Renal Disease}

As with other effects on target organ damage, the predominant beyond-BP effect of ARBs on the kidney is related to the reduction of inflammation and oxidative stress $[77,78]$ although stimulation of the angiotensin II type 2 receptor may also be important to the effects of ARBs on the kidney [79].

There is substantial evidence for the efficacy of ARBs in reducing microalbuminuria or slowing the progression to proteinuria and overt nephropathy. Notably, ARBs have been shown to be superior to CCBs in the irbesartan diabetic nephropathy trial (IDNT) [9], the microalbuminuria reduction with valsartan (MARVAL) study [80], and the recent Japanese valsartan amlodipine randomized trial (VART) study, in which valsartan significantly improved the secondary end point of urinary albumin to creatinine ratio (UACR) versus amlodipine $(-61.3 \%$ versus $+34.9 \%$; $P<0.0001)$ [81]. The randomized olmesartan and diabetes microalbuminuria prevention (ROADMAP) study sought to assess whether olmesartan could delay or prevent the occurrence of microalbuminuria in patients with type 2 diabetes and normoalbuminuria [82]. After a median 3.2 years, there was a nonsignificant increase $(17 \%)$ in the time to onset of microalbuminuria with olmesartan after adjustment for differences in BP reduction. However, this was accompanied by increased $\mathrm{CV}$ mortality versus placebo ( $0.7 \%$ versus $0.1 \% ; P=0.01)$.

Preclinical models have found that telmisartan also has direct protective effects on the kidney. In a rat model 
of glomerulonephritis, high-dose telmisartan ameliorated glomerular and tubulointerstitial damage [83]. Possible pathways included growth factor signaling, the mammalian target of rapamycin signaling, protein ubiquitination, the $\mathrm{Wnt} / \beta$ catenin pathway, and hypoxia signaling. Telmisartan also reduced the urinary albumin excretion rate (UAER) and proteinuria to a greater degree than amlodipine in a rat model of aldosterone-induced glomerular injury [84]. In spontaneously hypertensive rats fed with a high-fat diet, telmisartan was more effective than valsartan in reducing body weight, renal inflammation (MCP-1), and renal injury (UAER and glomerular damage) [85].

In humans, telmisartan improved renal endothelial function similar to ramipril in a randomized, double-blind study of 96 patients with hypertension and type 2 diabetes treated for 9 weeks [86]. This was accompanied by significant increases in nitric oxide activity of the renal endothelium (indicating reduced oxidative stress) with telmisartan $(P<$ $0.001)$ and ramipril $(P=0.018)$. Telmisartan significantly reduced the transition from incipient to overt nephropathy compared with placebo in the incipient to overt: Angiotensin II blocker, telmisartan, investigation on type 2 diabetic nephropathy (INNOVATION) study. This trial enrolled 527 hypertensive Japanese patients with type 2 diabetes who were treated with telmisartan or placebo for 52 weeks [87]. For the primary end point, the rates of transition from incipient to overt nephropathy were significantly lower for telmisartan $80 \mathrm{mg}(16.7 \%)$ and telmisartan $40 \mathrm{mg}$ (22.6\%) compared with placebo (49.9\%) (both $P<0.0001$ ). BP reductions were similar across groups. Telmisartan and enalapril were found to be similarly effective in slowing the loss of glomerular filtration rate (GFR) in the diabetics exposed to telmisartan and enalapril (DETAIL) study, in which 250 patients with early nephropathy (normal GFR but UAER between 11 and $999 \mu \mathrm{g}$ per minute) were randomized to telmisartan $80 \mathrm{mg}$ or enalapril $20 \mathrm{mg}$ daily for 5 years [88]. The mean change in the GFR with telmisartan compared with enalapril was -17.9 versus $-14.9 \mathrm{~mL} / \mathrm{minute} / 1.73 \mathrm{~m}^{2}$ (difference $-3.0 ; 95 \%$ CI, -7.6-1.6). A subgroup analysis of ONTARGET showed that the rate of the primary renal outcome (a composite of dialysis, doubling of serum creatinine, and death) was similar for telmisartan and ramipril (13.4\% versus $13.5 \%$; HR, 1.00; 95\% CI, 0.92-1.09) [89]. In the TRANSCEND study, progression of albuminuria was significantly lower with telmisartan than with placebo $(32 \%$ versus $63 \%$; $P<$ 0.001) [89].

Telmisartan has been found to exert a greater antiproteinuric effect than losartan. In A telmisartan $80 \mathrm{mg}$ versus losartan $100 \mathrm{mg}$ in hypertensive type-2 diabEtic patients with overt nephropathy (AMADEO) study, 860 patients with diabetic nephropathy were treated with telmisartan or losartan for 1 year. Despite matched BP reductions, telmisartan provided a significantly greater reduction in UACR compared with losartan $(29.8 \%$ versus $21.4 \% ; P=$ 0.03) [90]. In a related study, the trial to investigate the efficacy of telmIsartan versus valsartan in hypertensive type 2 diabetic patients with overt nephropathy (VIVALDI) found similar reductions in 24-hour UAER with telmisartan $80 \mathrm{mg}$ versus valsartan $160 \mathrm{mg}$ in 885 patients with hypertension and diabetic nephropathy (33\% reduction in both groups, although patients in the valsartan group required additional antihypertensive comedication) [91]. However, the inflammatory parameter, urinary excretion of 8-iso-prostaglandin $\mathrm{F}_{2 \alpha}$ (8-iso-PGF $\mathrm{P}_{2 \alpha}$ ), decreased significantly more with telmisartan versus valsartan $(14 \%$ versus $7 \%, P=0.040)$.

\section{LVH and Cardiac Remodeling}

LVH is a common form of target organ damage associated with hypertension that increases the risk for CV morbidity and mortality [92], and, as with other forms of target organ damage, angiotensin II plays a central role in promoting LVH [93]. ARBs as a class are among the most effective antihypertensives in reducing LVH [94], an effect that is probably due to their interruption of the fibrotic and trophic effects of angiotensin II [95].

In rat/mouse models of LVH, telmisartan has shown beneficial effects on reducing endoplasmic reticulum stress, apoptosis, and indexes of cardiac hypertrophy [96, 97]. In one study, the development of LVH in rats was accompanied by changes in the expression of 17 proteins, primarily involved in cell structure, metabolism, stress, and signal transduction. Importantly, these changes were prevented or attenuated by telmisartan treatment [98]. Telmisartan has also been found to improve left ventricular function significantly and ameliorate the progression of cardiac remodeling in rats with chronic heart failure [99]. Activation of PPAR $\gamma$-dependent pathways are thought to be involved in development of cardiac hypertrophy, and several studies have investigated whether PPAR $\gamma$ modulation with telmisartan contributes to its effects on LVH. In a rat model of MI, telmisartan prevented cardiac remodeling by reducing cardiac hypertrophy and fibrosis; this study suggested that the mechanisms involved an anti-inflammatory effect and PPAR $\gamma$ activation in addition to suppression of angiotensin II activity [100]. In diabetic rats, telmisartan improved ischemia/reperfusion injury, whereas a PPAR $\gamma$ antagonist worsened ischemia/reperfusion injury, suggestive of a role for PPAR $\gamma$ activation [101]. In a hypertensive rat model, both telmisartan and olmesartan had beneficial effects on cardiac structure and function [102]. As olmesartan has little PPAR $y$ activity, this indicates that the mechanism may be pressor related or $\mathrm{AT}_{1}$ receptor dependent, and other recent research suggests that pioglitazone may not attenuate the development of LVH [103].

Telmisartan is more effective than HCTZ and carvedilol in regressing $\mathrm{LVH}$, which supports other evidence that RAS blockers have particular efficacy on this outcome [104, 105]. Similarly in TRANSCEND, telmisartan significantly reduced the risk of developing LVH compared with placebo (most patients received non-ARB/ACE inhibitor antihypertensive therapy) by $21 \%$ overall (OR, $0.79 ; 95 \%$ CI, $0.68-0.91$; $P=0.0017)$ and by $37 \%$ for new-onset LVH (OR, 0.63; $95 \%$ CI, $0.51-0.79 ; P=0.0001)$ [106]. Overall, the effects of telmisartan on LVH appear to be similar to those of other RAS blockers. In patients with acute MI, telmisartan was equivalent to enalapril in suppressing vascular inflammation and reducing LVH [107]. In a subgroup analysis of 287 
patients who underwent magnetic resonance imaging in ONTARGET, telmisartan was equivalent to ramipril in improving left ventricular mass (LVM) and volume at 2 years [108]. In hypertensive patients, reductions in LVM were similar with telmisartan (11.4\%) and ramipril (9.9\%), despite similar BP reductions in the groups [109]. One small doubleblind study of hypertensive patients (nine with LVH) showed that telmisartan or losartan for 6 months provided similar reductions in LVM index and BP [110].

\section{Atrial Fibrillation}

One functional consequence of the effects of RAS blockade on cardiac remodeling may be a reduction in the incidence of atrial fibrillation (AF). For example, in the LIFE study, 8851 hypertensive patients at risk of AF were followed up for 5 years. New-onset AF was significantly reduced by losartan compared with the $\beta$-blocker atenolol (6.8 versus 10.1 per 1000 person-years; relative risk 0.67; 95\% CI, $0.55-$ $0.83 ; P<0.001)$, despite similar BP reductions [111]. This hypothesis was supported by two meta-analyses: firstly, 23 randomized, controlled trials $(n=87,048)$ found that ARBs and ACE inhibitors reduced the OR for primary or secondary AF by $33 \%(P<0.00001)$ [112]. In a second meta-analysis of 11 randomized controlled trials $(n=56,308)$, the relative risk of primary or secondary AF was reduced by both ARBs (29\%, $P=0.00002)$ and ACE inhibitors $(28 \%, P=0.01)$ [113].

However, more recent randomized, placebo-controlled studies of valsartan, olmesartan, and irbesartan have been disappointing [114-116]. Valsartan and placebo were associated with similar rates of recurrent AF over 1 year in patients with previous AF as well as CV disease, diabetes, or left atrial enlargement (51.4\% versus 52.1\%; adjusted HR, 0.97; 96\% CI, 0.83-1.14; $P=0.73$ ) [114]. Olmesartan and placebo groups had similar rates of AF burden (percentage of days with paroxysmal AF) over 12 months in a study of patients with documented paroxysmal AF without structural heart disease [115]. In high-risk patients with AF, for 4 years irbesartan and placebo were associated with similar rates of composite CV outcome (risk of stroke, MI, or death from vascular causes) (5.4\% versus $5.4 \%$ per 100 person-years; HR, 0.99 ; 95\% CI, 0.91-1.08; $P=0.85)$ or this composite outcome plus hospitalization for heart failure $(7.3 \%$ versus 7.7\% per 100 person-years; HR, 0.94; 95\% CI, 0.87-1.02; $P=0.12)[116]$.

In contrast to recent studies with other ARBs, clinical trials with telmisartan have shown reductions in the incidence of AF. In the high-CV-risk patients in ONTARGET, telmisartan was as effective as ramipril on the end point of new-onset $\mathrm{AF}$ (with an incidence of $6.7 \%$ versus $6.9 \%$, resp.) [6]. In hypertensive patients with the metabolic syndrome and a history of AF, telmisartan was more effective than ramipril in reducing the recurrence of AF over 1 year $(12.9 \%$ versus $25.5 \%$; $P<0.05$ ) as well as the severity of AF, despite a similar BP reduction [117]. In patients with hypertension and a history of AF, telmisartan was associated with a significantly lower rate of new episodes of AF compared with the $\beta$ blocker, carvedilol (14.3\% versus $37.1 \% ; P<0.003$ ), again despite a similar BP reduction [118].

\section{Cerebrovascular Disease}

Angiotensin II may contribute to the pathogenesis of stroke [119]. Recently, in stroke-prone spontaneously hypertensive rats, telmisartan, ramipril, and the combination had similar beneficial effects on stroke incidence. However, telmisartan and telmisartan/ramipril provided superior neuroprotection compared with ramipril alone in normotensive rats with induced cerebral ischemia, as shown by improved nitric oxide, reduced infarct volume, and inflammation ( TNF $\alpha$ ), and induced neurotrophin receptor and neuronal survival [120]. In the PRoFESS trial in 20,332 patients, telmisartan initiated soon after an ischemic stroke did not significantly reduce the rate of recurrent stroke, major CV events, or newonset diabetes compared with standard care over a 2.5-year period [121]. However, in a post-hoc exploratory analysis, the rate of recurrent stroke was lower with telmisartan compared with standard care after 6 months $(5.3 \%$ versus 6.0\%; HR, 0.88; 95\% CI, 0.78-0.99) [121].

Antihypertensive medications may reduce the incidence of Alzheimer's disease. In a randomized study of elderly hypertensive patients with probable Alzheimer's disease, 6month treatment with telmisartan reduced cognitive decline compared with amlodipine [122]. Cognitive function test scores were unchanged in the telmisartan group and significantly higher in the amlodipine group. In addition, telmisartan increased cerebral blood flow in the right supramarginal gyrus, superior parietal lobule, cuneus, and lingual gyrus compared with amlodipine, while amlodipine increased cerebral blood flow only in the right cingulate gyrus compared with telmisartan.

\section{Conclusions}

The ONTARGET trial was a landmark for clinical practice, proving for the first time that an ARB, telmisartan, could prevent $\mathrm{CV}$ events in high-CV-risk patients to a degree similar to ramipril. Since $\mathrm{CV}$ disease occurs as a progressive continuum, such effects on CV outcomes imply an effect on the underlying disease pathology as well as intermediate end points, such as target organ damage. This review has sought to investigate the evidence for telmisartan's effects on these $\mathrm{CV}$ disease processes, with a view to assisting in interpretation of the ONTARGET trial results.

There is substantial evidence, reviewed here, that blockade of the angiotensin II receptor by telmisartan has a direct and beneficial effect of key aspects of CV disease. In common with other blockers of the RAS, telmisartan has been shown to reduce inflammation and oxidative stress, which is the most important process linking the direct effect of angiotensin II to CV disease progression. This likely explains the effects observed on vascular wall stiffness and downstream effects on target organ damage, such as reduced albuminuria and renal dysfunction, reduced $\mathrm{LVH}$, and reduced risk of AF. Telmisartan also improves metabolic parameters, an effect that may be due to RAS blockade but 
which may also be related to telmisartan's ability to modulate PPAR $\gamma$.

The extent to which pharmacologic differences between ARBs translate into clinically meaningful effects is difficult to confirm, but, on the evidence reviewed here, telmisartan may have superior effects over certain other ARBs-with the strongest evidence being the superiority of telmisartan over losartan on the reduction in proteinuria in the AMADEO study. Since proteinuria is a strong indicator of CV risk, it seems reasonable to expect that differential effects between these two drugs on CV outcomes are likely.

In summary, the prevention of CV events with telmisartan observed in ONTARGET is likely to be a consequence of the direct effects of telmisartan on CV disease pathology, notably effects on inflammation and target organ damage. Differences exist between ARBs on these intermediate end points, which reflect differences in their pharmacology. Whether other ARBs have effects similar to telmisartan on $\mathrm{CV}$ outcomes remains to be tested.

\section{Conflict of Interests}

T. Unger has received speaker's honoraria and research grants from Bayer, Berlin Chemie, Boehringer Ingelheim, Merck, Novartis, Sanofi, and Takeda.

\section{Acknowledgments}

The author was fully responsible for all content and editorial decisions, was involved at all stages of manuscript development, and has approved the final version of the review that reflects the author's interpretation and conclusions. Medical writing assistance, supported financially by Boehringer Ingelheim, was provided by Sharon Rayner $\mathrm{PhD}$ and Tomas Rees PhD, of PAREXEL during the preparation of this review. Boehringer Ingelheim was given the opportunity to check the data used in the manuscript for factual accuracy only.

\section{References}

[1] T. Unger, "The role of the renin-angiotensin system in the development of cardiovascular disease," American Journal of Cardiology, vol. 89, no. 2, pp. 3A-9A, 2002.

[2] B. J. Hoogwerf, "Renin-angiotensin system blockade and cardiovascular and renal protection," American Journal of Cardiology, vol. 105, no. 1, supplement, pp. 30A-35A, 2010.

[3] V. Dzau and E. Braunwald, "Resolved and unresolved issues in the prevention and treatment of coronary artery disease: a workshop consensus statement," American Heart Journal, vol. 121, no. 4, pp. 1244-1263, 1991.

[4] B. Dahlöf, R. B. Devereux, S. E. Kjeldsen et al., "Cardiovascular morbidity and mortality in the Losartan Intervention For Endpoint reduction in hypertension study (LIFE): a randomised trial against atenolol," The Lancet, vol. 359, no. 9311, pp. 995-1003, 2002.

[5] T. Sawada, H. Yamada, B. Dahlöf, and H. Matsubara, "Effects of valsartan on morbidity and mortality in uncontrolled hypertensive patients with high cardiovascular risks: KYOTO heart study," European Heart Journal, vol. 30, no. 20, pp. 2461-2469, 2009.
[6] S. Yusuf, K. K. Teo, J. Pogue et al., "Telmisartan, ramipril, or both in patients at high risk for vascular events. ONTARGET Investigators," The New England Journal of Medicine, vol. 358, no. 15, pp. 1547-1559, 2008.

[7] S. Mochizuki, B. Dahlöf, M. Shimizu et al., "Valsartan in a Japanese population with hypertension and other cardiovascular disease (Jikei Heart Study): a randomised, open-label, blinded endpoint morbidity-mortality study," The Lancet, vol. 369, no. 9571, pp. 1431-1439, 2007.

[8] M. A. Pfeffer, J. J. V. McMurray, E. J. Velazquez et al., "Valsartan, captopril, or both in myocardial infarction complicated by heart failure, left ventricular dysfunction, or both," The New England Journal of Medicine, vol. 349, no. 20, pp. 18931906, 2003.

[9] E. J. Lewis, L. G. Hunsicker, W. R. Clarke et al., "Renoprotective effect of the angiotensin-receptor antagonist irbesartan in patients with nephropathy due to type 2 diabetes," The New England Journal of Medicine, vol. 345, no. 12, pp. 851860, 2001.

[10] G. Mancia, T. Unger, and A. Zanchetti, "Introduction: reducing cardiovascular risk: ONTARGET a new standard in cardiovascular protection," Journal of Hypertension, vol. 27, no. 5, p. S1, 2009.

[11] Micardis(Telmisartan) Tablets, Prescribing Information, Boehringer Ingelheim International $\mathrm{GmbH}$, Ingelheim, Germany, 2011, http://bidocs.boehringer-ingelheim.com/BIWebAccess/ViewServlet.ser ? docBase=renetnt\&folderPath=/ Prescribing+Information/PIs/Micardis+Tabs/MICARDIS2040-80mg.PDF.

[12] D. L. Keefe, "Clinical pharmacology of telmisartan," Journal of Clinical Pharmacology, vol. 40, no. 12, part 1, p. 1311, 2000.

[13] A. Chiolero and M. Burnier, "Pharmacology of valsartan, an angiotensin II receptor antagonist," Expert Opinion on Investigational Drugs, vol. 7, no. 11, pp. 1915-1925, 1998.

[14] D. Galzerano, C. Capogrosso, S. di Michele et al., "New standards in hypertension and cardiovascular risk management: focus on telmisartan," Vascular Health and Risk Management, vol. 6, no. 1, pp. 113-133, 2010.

[15] V. Mauno, K. Hannu, and K. Esko, "Proinflammation and hypertension: a population-based study," Mediators of Inflammation, vol. 2008, Article ID 619704, 2008.

[16] M. Ekholm, T. Kahan, G. Jörneskog, A. Bröijersen, and N. H. Wallén, "Angiotensin II infusion in man is proinflammatory but has no short-term effects on thrombin generation in vivo," Thrombosis Research, vol. 124, no. 1, pp. 110-115, 2009.

[17] F. Nemati, N. Rahbar-Roshandel, F. Hosseini, M. Mahmoudian, and M. Shafiei, "Anti-inflammatory effects of anti-hypertensive agents: influence on interleukin-1 $\beta$ secretion by peripheral blood polymorphonuclear leukocytes from patients with essential hypertension," Clinical and Experimental Hypertension, vol. 33, no. 2, pp. 66-76, 2011.

[18] T. Shishido, T. Konta, S. Nishiyama et al., "Suppressive effects of valsartan on microalbuminuria and CRP in patients with metabolic syndrome (Val-Mets)," Clinical and Experimental Hypertension, vol. 33, no. 2, pp. 117-123, 2011.

[19] G. Derosa, P. Maffioli, S. A. T. Salvadeo et al., "Candesartan effect on inflammation in hypertension," Hypertension Research, vol. 33, no. 3, pp. 209-213, 2010.

[20] U. Kintscher, N. Marx, P. Martus et al., "Effect of high-dose valsartan on inflammatory and lipid parameters in patients with Type 2 diabetes and hypertension," Diabetes Research and Clinical Practice, vol. 89, no. 3, pp. 209-215, 2010. 
[21] B. Schieffer, C. Bünte, J. Witte et al., "Comparative effects of AT1-antagonism and angiotensin-converting enzyme inhibition on markers of inflammation and platelet aggregation in patients with coronary artery disease," Journal of the American College of Cardiology, vol. 44, no. 2, pp. 362-368, 2004.

[22] D. Fliser, K. Buchholz, and H. Haller, "Antiinflammatory effects of angiotensin II subtype 1 receptor blockade in hypertensive patients with microinflammation," Circulation, vol. 110, no. 9, pp. 1103-1107, 2004.

[23] V. Sukumaran, K. Watanabe, P. T. Veeraveedu et al., "Telmisartan ameliorates experimental autoimmune myocarditis associated with inhibition of inflammation and oxidative stress," European Journal of Pharmacology, vol. 652, no. 1-3, pp. 126-135, 2011.

[24] M. Kubota, M. Shimizu, H. Sakai et al., "Renin-angiotensin system inhibitors suppress azoxymethane-induced colonic preneoplastic lesions in C57BL/KsJ-db/db obese mice," Biochemical and Biophysical Research Communications, vol. 410, no. 1, pp. 108-113, 2011.

[25] E. Blessing, M. Preusch, R. Kranzhöfer et al., "Anti-atherosclerotic properties of telmisartan in advanced atherosclerotic lesions in apolipoprotein E deficient mice," Atherosclerosis, vol. 199, no. 2, pp. 295-303, 2008.

[26] S. Cianchetti, A. Del Fiorentino, R. Colognato, R. Di Stefano, F. Franzoni, and R. Pedrinelli, "Anti-inflammatory and antioxidant properties of telmisartan in cultured human umbilical vein endothelial cells," Atherosclerosis, vol. 198, no. 1, pp. 22-28, 2008.

[27] S. J. Hong, W. J. Shim, J. I. Choi et al., "Comparison of effects of telmisartan and valsartan on late lumen loss and inflammatory markers after sirolimus-eluting stent implantation in hypertensive patients," American Journal of Cardiology, vol. 100, no. 11, pp. 1625-1629, 2007.

[28] Y. Yano, S. Hoshide, J. Ishikawa et al., "The differential effects of angiotensin II type 1 receptor blockers on microalbuminuria in relation to low-grade inflammation in metabolic hypertensive patients," American Journal of Hypertension, vol. 20, no. 5, pp. 565-572, 2007.

[29] R. A. Payne, I. B. Wilkinson, and D. J. Webb, "Arterial stiffness and hypertension: emerging concepts," Hypertension, vol. 55, no. 1, pp. 9-14, 2010.

[30] G. F. Mitchell, S. J. Hwang, R. S. Vasan et al., "Arterial stiffness and cardiovascular events: the framingham heart study," Circulation, vol. 121, no. 4, pp. 505-511, 2010.

[31] T. Coutinho, S. T. Turner, and I. J. Kullo, "Aortic pulse wave velocity is associated with measures of subclinical target organ damage," JACC: Cardiovascular Imaging, vol. 4, no. 7, pp. 754-761, 2011.

[32] Y. Ono, Y. Nakaya, S. Bando, T. Soeki, S. Ito, and M. Sata, "Telmisartan decreases plasma levels of asymmetrical dimethyl-L-arginine and improves lipid and glucose metabolism and vascular function," International Heart Journal, vol. 50, no. 1, pp. 73-83, 2009.

[33] D. Chujo, K. Yagi, A. Asano et al., “Telmisartan treatment decreases visceral fat accumulation and improves serum levels of adiponectin and vascular inflammation markers in Japanese hypertensive patients," Hypertension Research, vol. 30, no. 12, pp. 1205-1210, 2007.

[34] S. Morimoto, Y. Yano, K. Maki, and K. Sawada, "Renal and vascular protective effects of telmisartan in patients with essential hypertension," Hypertension Research, vol. 29, no. 8, pp. 567-572, 2006.
[35] H. Uchida, Y. Nakamura, M. Kaihara et al., "Practical efficacy of telmisartan for decreasing morning home blood pressure and pulse wave velocity in patients with mild-to-moderate hypertension," Hypertension Research, vol. 27, no. 8, pp. 545550, 2004.

[36] R. Asmar, P. Gosse, J. Topouchian, G. N’tela, A. Dudley, and G. L. Shepherd, "Effects of telmisartan on arterial stiffness in type 2 diabetes patients with esssential hypertension," JRAAS-Journal of the Renin-Angiotensin-Aldosterone System, vol. 3, no. 3, pp. 176-180, 2002.

[37] R. Asmar, "Effect of telmisartan on arterial distensibility and central blood pressure in patients with mild to moderate hypertension and Type 2 diabetes mellitus," JRAAS_Journal of the Renin-Angiotensin-Aldosterone System, vol. 2, no. 2, supplement, pp. S8-S11, 2001.

[38] T. Nakamura, T. Inoue, T. Suzuki et al., "Comparison of renal and vascular protective effects between telmisartan and amlodipine in hypertensive patients with chronic kidney disease with mild renal insufficiency," Hypertension Research, vol. 31, no. 5, pp. 841-850, 2008.

[39] K. Kinouchi, A. Ichihara, M. Sakoda, A. Kurauchi-Mito, K. Murohashi-Bokuda, and H. Itoh, "Effects of telmisartan on arterial stiffness assessed by the cardio-ankle vascular index in hypertensive patients," Kidney and Blood Pressure Research, vol. 33, no. 4, pp. 304-312, 2010.

[40] A. Daugherty and L. A. Cassis, "Mechanisms of abdominal aortic aneurysm formation," Current Atherosclerosis Reports, vol. 4, no. 3, pp. 222-227, 2002.

[41] S. Matsumoto, K. Kamide, F. Banno et al., "Impact of RGS2 deficiency on the therapeutic effect of telmisartan in angiotensin II-induced aortic aneurysm," Hypertension Research, vol. 33, no. 12, pp. 1244-1249, 2010.

[42] E. Kaschina, F. Schrader, M. Sommerfeld et al., "Telmisartan prevents aneurysm progression in the rat by inhibiting proteolysis, apoptosis and inflammation," Journal of Hypertension, vol. 26, no. 12, pp. 2361-2373, 2008.

[43] S. Takai, K. Kirimura, D. Jin et al., "Significance of angiotensin II receptor blocker lipophilicities and their protective effect against vascular remodeling," Hypertension Research, vol. 28, no. 7, pp. 593-600, 2005.

[44] S. C. Benson, R. Iguchi, C. I. Ho, K. Yamamoto, and T. W. Kurtz, "Inhibition of cardiovascular cell proliferation by angiotensin receptor blockers: are all molecules the same?" Journal of Hypertension, vol. 26, no. 5, pp. 973-980, 2008.

[45] H. Hasegawa, H. Takano, H. Narumi et al., "Effects of telmisartan and losartan on cardiovascular protection in Japanese hypertensive patients," Hypertension Research, vol. 34, no. 11, pp. 1179-1184, 2011.

[46] K. A. M. Jandeleit-Dahm, C. Tikellis, C. M. Reid, C. I. Johnston, and M. E. Cooper, "Why blockade of the reninangiotensin system reduces the incidence of new-onset diabetes," Journal of Hypertension, vol. 23, no. 3, pp. 463-473, 2005.

[47] A. J. Scheen, "Prevention of type 2 diabetes mellitus through inhibition of the renin-angiotensin system," Drugs, vol. 64, no. 22, pp. 2537-2565, 2004.

[48] W. J. Elliott and P. M. Meyer, "Incident diabetes in clinical trials of antihypertensive drugs: a network meta-analysis," The Lancet, vol. 369, no. 9557, pp. 201-207, 2007.

[49] S. Julius, S. E. Kjeldsen, M. Weber et al., "Outcomes in hypertensive patients at high cardiovascular risk treated with regimens based on valsartan or amlodipine: the VALUE randomised trial," The Lancet, vol. 363, no. 9426, pp. 20222031, 2004. 
[50] J. J. McMurray, R. R. Holman, S. M. Haffner et al., "Effect of valsartan on the incidence of diabetes and cardiovascular events," The New England Journal of Medicine, vol. 362, no. 16, pp. 1477-1490, 2010.

[51] S. Yusuf, K. Teo, C. Anderson et al., "Effects of the angiotensin-receptor blocker telmisartan on cardiovascular events in high-risk patients intolerant to angiotensinconverting enzyme inhibitors: a randomised controlled trial," The Lancet, vol. 372, no. 9644, pp. 1174-1183, 2008.

[52] J. I. Barzilay, P. Gao, L. Rydén et al., "Effects of telmisartan on glucose levels in people at high risk for cardiovascular disease but free from diabetes: the TRANSCEND study," Diabetes Care, vol. 34, no. 9, pp. 1902-1907, 2011.

[53] T. W. Kurtz and U. Klein, "Next generation multifunctional angiotensin receptor blockers," Hypertension Research, vol. 32, no. 10, pp. 826-834, 2009.

[54] M. Clemenz, N. Frost, M. Schupp et al., "Liver-specific peroxisome proliferator-activated receptor $\alpha$ target gene regulation by the angiotensin type 1 receptor blocker telmisartan," Diabetes, vol. 57, no. 5, pp. 1405-1413, 2008.

[55] M. Schupp, M. Clemenz, R. Gineste et al., "Molecular characterization of new selective peroxisome proliferatoractivated receptor $\gamma$ modulators with angiotensin receptor blocking activity," Diabetes, vol. 54, no. 12, pp. 3442-3452, 2005.

[56] M. Schupp, J. Janke, R. Clasen, T. Unger, and U. Kintscher, "Angiotensin type 1 receptor blockers induce peroxisome proliferator-activated receptor-gamma activity," Circulation, vol. 109, no. 17, pp. 2054-2057, 2004.

[57] M. E. Marketou, J. E. Kontaraki, N. A. Tsakountakis et al., "Differential effect of telmisartan and amlodipine on monocyte chemoattractant protein-1 and peroxisome proliferatoractivated receptor-gamma gene expression in peripheral monocytes in patients with essential hypertension," American Journal of Cardiology, vol. 107, no. 1, pp. 59-63, 2011.

[58] I.-N. Bähr, P. Tretter, J. Krüger et al., "High-dose treatment with telmisartan induces monocytic peroxisome proliferatoractivated receptor $\gamma$ target genes in patients with the metabolic syndrome," Hypertension, vol. 58, no. 4, pp. 725732, 2011.

[59] H. He, D. Yang, L. Ma et al., "Telmisartan prevents weight gain and obesity through activation of peroxisome proliferator-activated receptor- $\delta$-dependent pathways," Hypertension, vol. 55, no. 4, pp. 869-879, 2010.

[60] K. Kappert, O. Tsuprykov, J. Kaufmann et al., "Chronic treatment with losartan results in sufficient serum levels of the metaboliteEXP3179 for PPAR $\gamma$ activation," Hypertension, vol. 54, no. 4, pp. 738-743, 2009.

[61] L. Yuan, X. Li, J. Li, H. L. Li, and S. S. Cheng, "Effects of renin-angiotensin system blockade on the islet morphology and function in rats with long-term high-fat diet," Acta Diabetologica. In press.

[62] R. Clasen, M. Schupp, A. Foryst-Ludwig et al., "PPAR $\gamma$ activating angiotensin type-1 receptor blockers induce adiponectin," Hypertension, vol. 46, no. 1, pp. 137-143, 2005.

[63] H. Furukawa, K. Mawatari, K. Koyama et al., "Telmisartan increases localization of glucose transporter 4 to the plasma membrane and increases glucose uptake via peroxisome proliferator-activated receptor $\gamma$ in 3T3-L1 adipocytes," European Journal of Pharmacology, vol. 660, no. 2-3, pp. 485491, 2011.

[64] A. Foryst-Ludwig, M. Hartge, M. Clemenz et al., "PPARgamma activation attenuates T-lymphocyte-dependent inflammation of adipose tissue and development of insulin resistance in obese mice," Cardiovascular Diabetology, vol. 9, article 64, 2010.

[65] F. Younis, N. Stern, R. Limor, Y. Oron, S. Zangen, and T. Rosenthal, "Telmisartan ameliorates hyperglycemia and metabolic profile in nonobese Cohen-Rosenthal diabetic hypertensive rats via peroxisome proliferator activator receptor- $\gamma$ activation," Metabolism, vol. 59, no. 8, pp. 1200-1209, 2010.

[66] P. Ernsberger and R. J. Koletsky, "Metabolic actions of angiotensin receptor antagonists: PPAR- $\gamma$ agonist actions or a class effect?" Current Opinion in Pharmacology, vol. 7, no. 2, pp. 140-145, 2007.

[67] C. V. Rizos, H. J. Milionis, M. S. Kostapanos et al., "Effects of rosuvastatin combined with olmesartan, irbesartan, or telmisartan on indices of glucose metabolism in greek adults with impaired fasting glucose, hypertension, and mixed hyperlipidemia: a 24-week, randomized, open-label, prospective study," Clinical Therapeutics, vol. 32, no. 3, pp. 492-505, 2010.

[68] S. Makita, A. Abiko, Y. Naganuma, Y. Moriai, and M. Nakamura, "Effects of telmisartan on adiponectin levels and body weight in hypertensive patients with glucose intolerance," Metabolism, vol. 57, no. 10, pp. 1473-1478, 2008.

[69] C. Vitale, G. Mercuro, C. Castiglioni et al., "Metabolic effect of telmisartan and losartan in hypertensive patients with metabolic syndrome," Cardiovascular Diabetology, vol. 4, article 6, 2005.

[70] Y. Ichikawa, "Comparative effects of telmisartan and valsartan on insulin resistance in hypertensive patients with metabolic syndrome," Internal Medicine, vol. 46, no. 17, pp. 1331-1336, 2007.

[71] G. Derosa, A. F. G. Cicero, A. D’Angelo et al., "Telmisartan and irbesartan therapy in type 2 diabetic patients treated with rosiglitazone: effects on insulin-resistance, leptin and tumor necrosis factor- $\alpha$, Hypertension Research, vol. 29, no. 11, pp. 849-856, 2006.

[72] R. Negro, G. Formoso, and H. Hassan, "The effects of irbesartan and telmisartan on metabolic parameters and blood pressure in obese, insulin resistant, hypertensive patients," Journal of Endocrinological Investigation, vol. 29, no. 11, pp. 957-961, 2006.

[73] D. A. De Luis, R. Conde, M. González-Sagrado et al., "Effects of telmisartan vs olmesartan on metabolic parameters, insulin resistance and adipocytokines in hypertensive obese patients," Nutricion Hospitalaria, vol. 25, no. 2, pp. 275-279, 2010.

[74] M. Watanabe, K. Inukai, T. Sumita et al., "Effects of telmisartan on insulin resistance in Japanese Type 2 diabetic patients," Internal Medicine, vol. 49, no. 17, pp. 1843-1847, 2010.

[75] Y. Miura, N. Yamamoto, S. Tsunekawa et al., "Replacement of valsartan and candesartan by telmisartan in hypertensive patients with type 2 diabetes: metabolic and antiatherogenic consequences," Diabetes Care, vol. 28, no. 3, pp. 757-758, 2005.

[76] Y. Mori, T. Tanaka, K. Matsuura, J. Yokoyama, and K. Utsunomiya, "Influence of telmisartan on insulin response after glucose loading in obese patients with hypertension: ARB Trial of hypertension in obese patients with hyperinsulinemia assessed by oral glucose tolerance test (ATHLETE)," Advances in Therapy, vol. 28, no. 8, pp. 698-706, 2011.

[77] V. Kon, M. F. Linton, and S. Fazio, "Atherosclerosis in chronic kidney disease: the role of macrophages," Nature Reviews Nephrology, vol. 7, no. 1, pp. 45-54, 2011. 
[78] G. Remuzzi, N. Perico, M. Macia, and P. Ruggenenti, "The role of renin-angiotensin-aldosterone system in the progression of chronic kidney disease," Kidney International, vol. 68, no. 99, pp. S-57-S-65, 2005.

[79] U. O. Wenzel, C. Krebs, and R. Benndorf, "The angiotensin II type 2 receptor in renal disease," JRAAS-Journal of the Renin-Angiotensin-Aldosterone System, vol. 11, no. 1, pp. 3741, 2010.

[80] G. Viberti and N. M. Wheeldon, "Microalbuminuria reduction with valsartan in patients with type 2 diabetes mellitus: a blood pressure-independent effect," Circulation, vol. 106, no. 6, pp. 672-678, 2002.

[81] H. Narumi, H. Takano, S. Shindo et al., "Effects of valsartan and amlodipine on cardiorenal protection in Japanese hypertensive patients: the Valsartan Amlodipine Randomized Trial," Hypertension Research, vol. 34, no. 1, pp. 62-69, 2011.

[82] H. Haller, S. Ito, J. L. Izzo Jr. et al., "Olmesartan for the delay or prevention of microalbuminuria in type 2 diabetes," The New England Journal of Medicine, vol. 364, no. 10, pp. 907917, 2011.

[83] L. Villa, P. Boor, A. Konieczny et al., "Effects and mechanisms of angiotensin II receptor blockade with telmisartan in a normotensive model of mesangioproliferative nephritis," Nephrology Dialysis Transplantation, vol. 26, no. 10, pp. 3131-3143, 2011.

[84] W. Liang, C. Chen, J. Shi et al., "Disparate effects of eplerenone, amlodipine and telmisartan on podocyte injury in aldosterone-infused rats," Nephrology Dialysis Transplantation, vol. 26, no. 3, pp. 789-799, 2011.

[85] M. A. H. Khan and J. D. Imig, "Telmisartan provides better renal protection than Valsartan in a rat model of metabolic syndrome," American Journal of Hypertension, vol. 24, no. 7, pp. 816-821, 2011.

[86] R. E. Schmieder, C. Delles, A. Mimran, J. P. Fauvel, and L. M. Ruilope, "Impact of telmisartan versus ramipril on renal endothelial function in patients with hypertension and type 2 diabetes," Diabetes Care, vol. 30, no. 6, pp. 1351-1356, 2007.

[87] H. Makino, M. Haneda, T. Babazono et al., "Prevention of transition from incipient to overt nephropathy with telmisartan in patients with type 2 diabetes," Diabetes Care, vol. 30, no. 6, pp. 1577-1578, 2007.

[88] A. H. Barnett, S. C. Bain, P. Bouter et al., "Angiotensinreceptor blockade versus converting-enzyme inhibition in type 2 diabetes and nephropathy," The New England Journal of Medicine, vol. 351, no. 19, pp. 1952-1961, 2004.

[89] J. F. E. Mann, R. E. Schmieder, L. Dyal et al., "Effect of telmisartan on renal outcomes: a randomized trial," Annals of Internal Medicine, vol. 151, no. 1, pp. 1-10, 2009.

[90] G. Bakris, E. Burgess, M. Weir, G. Davidai, and S. Koval, "Telmisartan is more effective than losartan in reducing proteinuria in patients with diabetic nephropathy," Kidney International, vol. 74, no. 3, pp. 364-369, 2008.

[91] J. Galle, E. Schwedhelm, S. Pinnetti, R. H. Böger, and C. Wanner, "Antiproteinuric effects of angiotensin receptor blockers: telmisartan versus valsartan in hypertensive patients with type 2 diabetes mellitus and overt nephropathy," Nephrology Dialysis Transplantation, vol. 23, no. 10, pp. 3174-3183, 2008.

[92] P. Verdecchia, G. Carini, A. Circo et al., "Left Ventricular mass and cardiovascular morbidity in essential hypertension: the MAVI study," Journal of the American College of Cardiology, vol. 38, no. 7, pp. 1829-1835, 2001.

[93] P. J. Lijnen, V. V. Petrov, and R. H. Fagard, "Angiotensin IIinduced stimulation of collagen secretion and production in cardiac fibroblasts is mediated via angiotensin II subtype 1 receptors," JRAAS-Journal of the Renin-AngiotensinAldosterone System, vol. 2, no. 2, pp. 117-122, 2001.

[94] R. H. Fagard, H. Celis, L. Thijs, and S. Wouters, "Regression of left ventricular mass by antihypertensive treatment: a meta-analysis of randomized comparative studies," Hypertension, vol. 54, no. 5, pp. 1084-1091, 2009.

[95] C. Cuspidi, F. Negri, and A. Zanchetti, "Angiotensin II receptor blockers and cardiovascular protection: focus on left ventricular hypertrophy regression and atrial fibrillation prevention," Vascular Health and Risk Management, vol. 4, no. 1, pp. 67-73, 2008.

[96] H. S. Guan, H. J. Shangguan, Z. Shang, L. Yang, X. M. Meng, and S. B. Qiao, "Endoplasmic reticulum stress caused by left ventricular hypertrophy in rats: effects of telmisartan," The American Journal of the Medical Sciences, vol. 342, no. 4, pp. 318-323, 2011.

[97] M. H. Krieger, A. Di Lorenzo, C. Teutsch, K. Kauser, and W. C. Sessa, "Telmisartan regresses left ventricular hypertrophy in caveolin-1-deficient mice," Laboratory Investigation, vol. 90, no. 11, pp. 1573-1581, 2010.

[98] L. Liu, W. Wang, X. Meng et al., "Left ventricular hypertrophy induced by abdominal aortic banding and its prevention by angiotensin receptor blocker telmisartan-a proteomic analysis," Journal of Physiology and Biochemistry, vol. 66, no. 4, pp. 329-338, 2010.

[99] V. Sukumaran, K. Watanabe, P. T. Veeraveedu et al., "Telmisartan, an angiotensin-II receptor blocker ameliorates cardiac remodeling in rats with dilated cardiomyopathy," Hypertension Research, vol. 33, no. 7, pp. 695-702, 2010.

[100] Y. Maejima, H. Okada, G. Haraguchi et al., "Telmisartan, a unique $\mathrm{ARB}$, improves left ventricular remodeling of infarcted heart by activating PPAR gamma," Laboratory Investigation, vol. 91, no. 6, pp. 932-944, 2011.

[101] S. N. Goyal, S. Bharti, J. Bhatia, T. C. Nag, R. Ray, and D. S. Arya, "Telmisartan, a dual ARB/partial PPAR- $\gamma$ agonist, protects myocardium from ischaemic reperfusion injury in experimental diabetes," Diabetes, Obesity and Metabolism, vol. 13, no. 6, pp. 533-541, 2011.

[102] V. G. DeMarco, M. S. Johnson, J. Habibi et al., "Comparative analysis of telmisartan and olmesartan on cardiac function in the transgenic (mRen2)27 rat," American Journal of Physiology, vol. 300, no. 1, pp. H181-H190, 2011.

[103] C. S. Weiss, M. Hagenmüller, M. Pichler et al., "Activation of PPAR $\gamma$ by pioglitazone does not attenuate left ventricular hypertrophy following aortic banding in rats," NaunynSchmiedeberg's Archives of Pharmacology, vol. 381, no. 4, pp. 285-295, 2010.

[104] D. Galzerano, P. Tammaro, A. Cerciello et al., "Freehand three-dimensional echocardiographic evaluation of the effect of telmisartan compared with hydrochlorothiazide on left ventricular mass in hypertensive patients with mild-tomoderate hypertension: a multicentre study," Journal of Human Hypertension, vol. 18, no. 1, pp. 53-59, 2004.

[105] D. Galzerano, P. Tammaro, L. Del Viscovo et al., "Threedimensional echocardiographic and magnetic resonance assessment of the effect of telmisartan compared with carvedilol on left ventricular mass: a multicenter, randomized, longitudinal study," American Journal of Hypertension, vol. 18, no. 12, pp. 1563-1569, 2005.

[106] P. Verdecchia, P. Sleight, G. Mancia et al., "Effects of telmisartan, ramipril, and their combination on left ventricular hypertrophy in individuals at high vascular risk in the ongoing telmisartan alone and in combination with ramipril 
global end point trial and the telmisartan randomized assessment study in ACE intolerant subjects with cardiovascular disease," Circulation, vol. 120, no. 14, pp. 1380-1389, 2009.

[107] T. Yokota, T. Osanai, K. Hanada et al., "Effects of telmisartan on markers of ventricular remodeling in patients with acute myocardial infarction: comparison with enalapril," Heart and Vessels, vol. 25, no. 6, pp. 460-468, 2010.

[108] B. R. Cowan, A. A. Young, C. Anderson et al., "Left ventricular mass and volume with telmisartan, ramipril, or combination in patients with previous atherosclerotic events or with diabetes mellitus (from the ONgoing Telmisartan Alone and in Combination With Ramipril Global Endpoint Trial [ONTARGET])," American Journal of Cardiology, vol. 104, no. 11, pp. 1484-1489, 2009.

[109] J. Petrovic, D. Petrovic, N. Vukovic et al., "Ventricular and vascular remodelling-effects of the angiotensin II receptor blocker telmisartan and/or the angiotensin-converting enzyme inhibitor ramipril in hypertensive patients," Journal of International Medical Research, vol. 33, no. 1, pp. 39A-49A, 2005.

[110] B. Martina, T. Dieterle, J. P. Sigle, C. Surber, and E. Battegay, "Effects of telmisartan and losartan on left ventricular mass in mild-to-moderate hypertension: a randomized, doubleblind trial," Cardiology, vol. 99, no. 3, pp. 169-170, 2003.

[111] K. Wachtell, M. Lehto, E. Gerdts et al., "Angiotensin II receptor blockade reduces new-onset atrial fibrillation and subsequent stroke compared to atenolol: the Losartan Intervention for End point reduction in hypertension (LIFE) study," Journal of the American College of Cardiology, vol. 45, no. 5, pp. 712-719, 2005.

[112] M. P. Schneider, T. A. Hua, M. Böhm, K. Wachtell, S. E. Kjeldsen, and R. E. Schmieder, "Prevention of atrial fibrillation by Renin-Angiotensin system inhibition a meta-analysis," Journal of the American College of Cardiology, vol. 55, no. 21, pp. 2299-2307, 2010.

[113] J. S. Healey, A. Baranchuk, E. Crystal et al., "Prevention of atrial fibrillation with angiotensin-converting enzyme inhibitors and angiotensin receptor blockers: a meta-analysis," Journal of the American College of Cardiology, vol. 45, no. 11, pp. 1832-1839, 2005.

[114] M. Disertori, R. Latini, S. Barlera et al., "Valsartan for prevention of recurrent atrial fibrillation," The New England Journal of Medicine, vol. 360, no. 16, pp. 1606-1617, 2009.

[115] A. Goette, N. Kirchof, G. Breithardt et al., "ANTIPAF: angiotensin II-antagonist in paroxysmal atrial fibrillation trial," Presented at the European Sociuety of Cardiology (ESC), Stockholm, Sweden, August 2010, http://www.escardio.org/congresses/esc-2010/congress-reports/Pages/708-5ANTIPAF.aspx.

[116] S. Yusuf, J. S. Healey, J. Pogue et al., "Irbesartan in patients with atrial fibrillation," The New England Journal of Medicine, vol. 364, no. 10, pp. 928-938, 2011.

[117] R. Fogari, A. Mugellini, A. Zoppi et al., "Effect of telmisartan and ramipril on atrial fibrillation recurrence and severity in hypertensive patients with metabolic syndrome and recurrent symptomatic paroxysmal and persistent atrial fibrillation," Journal of Cardiovascular Pharmacology and Therapeutics, vol. 17, no. 1, pp. 34-43, 2012.

[118] D. Galzerano, S. Di Michele, G. Paolisso et al., "A multicenter, randomized study of telmisartan vs. carvedilol for prevention of atrial fibrillation recurrence in hypertensive patients," Journal of Renin-Angiotensin-Aldosterone System. In press.
[119] S. G. Chrysant, "Possible pathophysiologic mechanisms supporting the superior stroke protection of angiotensin receptor blockers compared to angiotensin-converting enzyme inhibitors: clinical and experimental evidence," Journal of Human Hypertension, vol. 19, no. 12, pp. 923-931, 2005.

[120] C. Thoene-Reineke, K. Rumschüssel, K. Schmerbach et al., "Prevention and intervention studies with telmisartan, ramipril and their combination in different rat stroke models," PLoS ONE, vol. 6, no. 8, article e23646, 2011.

[121] S. Yusuf, H.-C. Diener, R. L. Sacco et al., "Telmisartan to prevent recurrent stroke and cardiovascular events," The New England Journal of Medicine, vol. 359, no. 12, pp. 1225-1237, 2008.

[122] K. Kume, H. Hanyu, H. Sakurai, Y. Takada, T. Onuma, and T. Iwamoto, "Effects of telmisartan on cognition and regional cerebral blood flow in hypertensive patients with Alzheimer's disease," Geriatrics and Gerontology International, vol. 12, no. 2, pp. 207-214, 2012. 


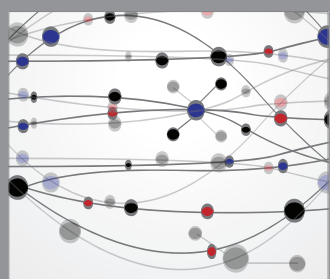

The Scientific World Journal
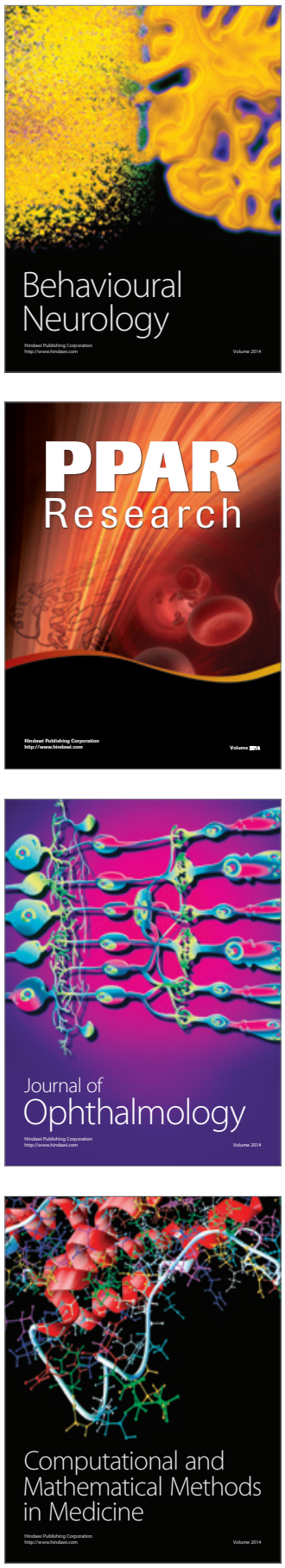

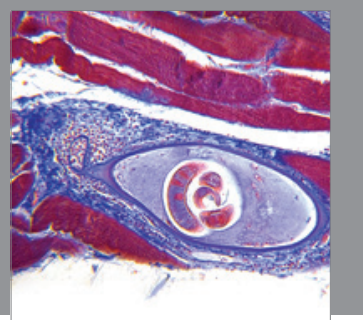

Gastroenterology

Research and Practice
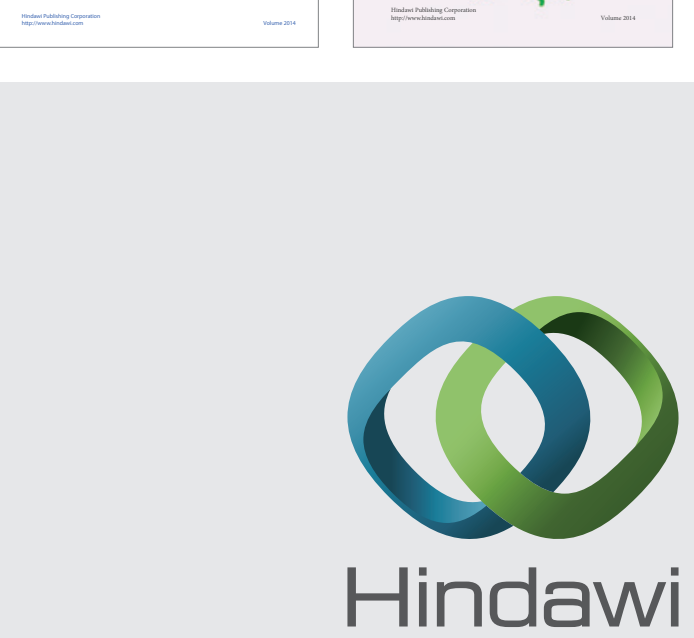

Submit your manuscripts at

http://www.hindawi.com
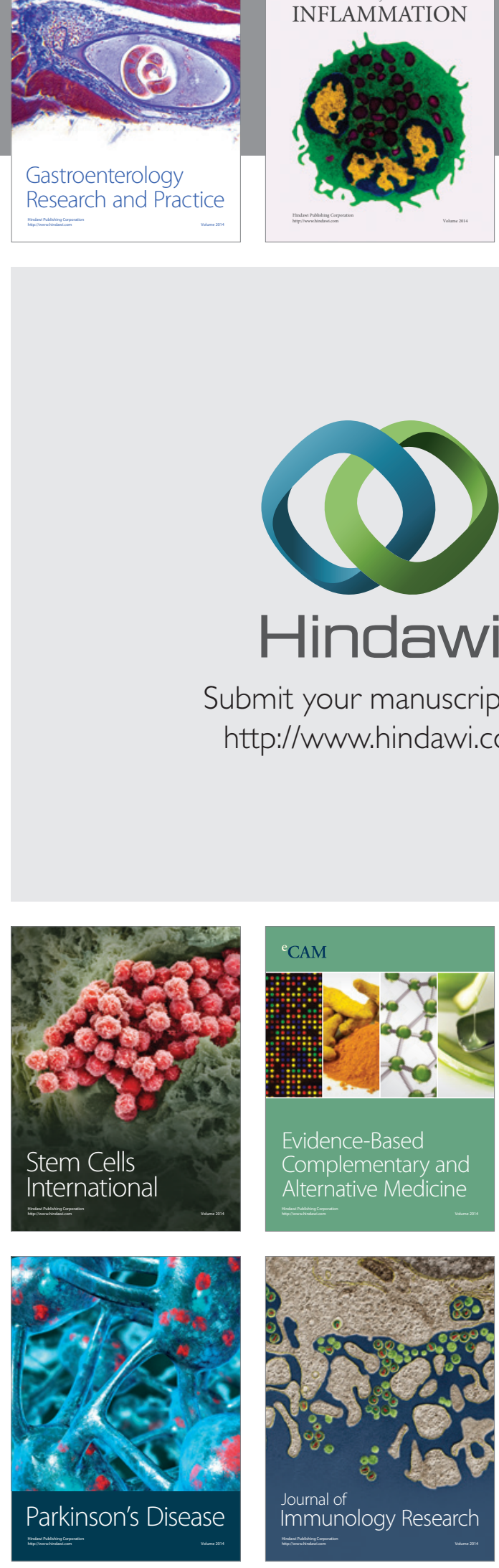

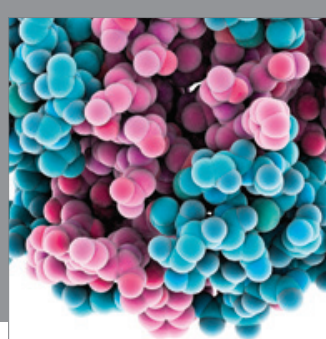

Diabetes Research
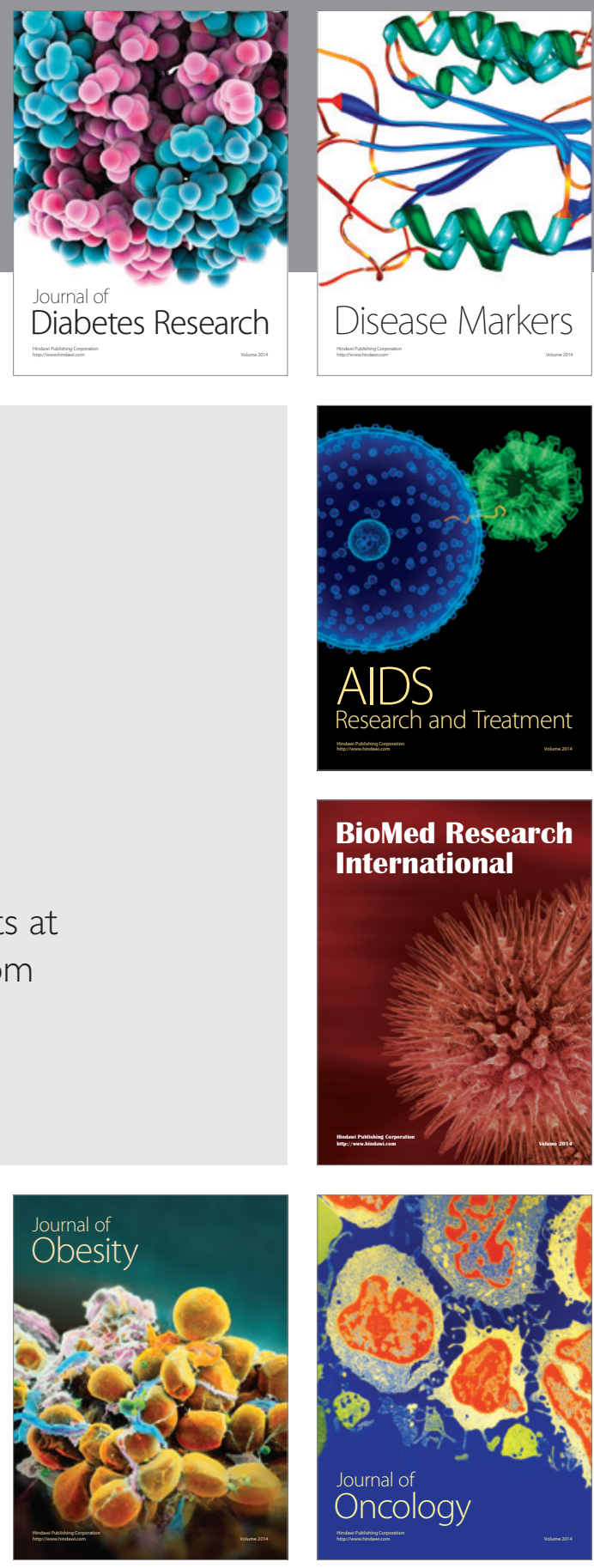

Disease Markers

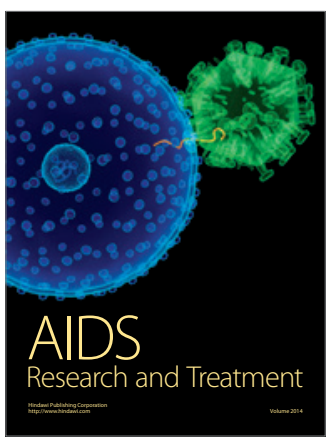

BioMed Research

International
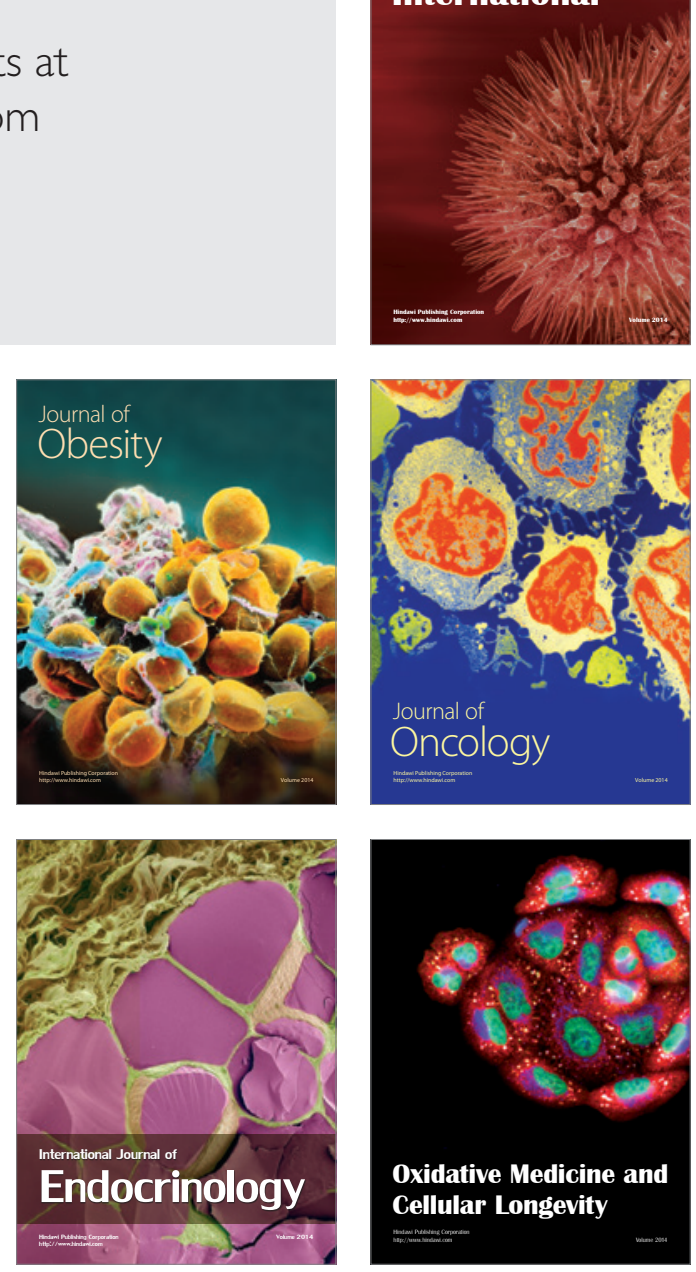